\title{
Assays of different aspects of haemostasis - what do they measure?
}

\author{
Nahreen Tynngård ${ }^{1,2}$, Tomas L Lindahl ${ }^{1}$ and Sofia Ramström ${ }^{3^{*}}$
}

\begin{abstract}
Haemostasis is a complex process affected by many factors including both cellular and plasma components. It is a multistep process starting with platelet adhesion to damaged endothelium and ending in clot fibrinolysis. There are several methods available to study different aspects of haemostasis including adhesion, aggregation, coagulation and fibrinolysis. This review describes the different methods, what aspects of haemostasis they measure and their limitations. Methods discussed include methods to study adhesion (e.g. PFA-100, cone and platelet(let) analyzer and perfusion chambers) and aggregation (e.g. Multiplate, VerifyNow and Plateletworks). Furthermore the principles behind viscoelastic haemostatic assays are presented as well as methods that can analyse aspects of haemostasis in plasma or platelet-rich-plasma samples (thrombin generation, overall haemostasis potential and Thrombodynamics Analyzer).
\end{abstract}

Keywords: Coagulation, Haemostasis, Platelets, Coagulation assays, Platelet function testing

\section{Introduction}

Haemostasis is a complex process involving adhesion of platelets to damaged endothelium, formation of a platelet plug (aggregation), formation of a fibrin network to stabilise the plug, clot retraction and finally fibrinolysis. In addition all of these processes take place under flow and is controlled and regulated by factors released from the surrounding endothelium. Surgery may cause coagulopathy due to acidosis, hypothermia and haemodilution and is associated with increased fibrinolytic activity which warrants monitoring to guide transfusion therapy $[1,2]$.

Thus an "ideal" haemostasis assay should preferably measure all these processes at relevant shear conditions and provide results in a timely manner. Indeed, there are many different methods available for measuring one or more of the many diverse events of the haemostatic process and platelet function. However, none of the methods currently available measures all these processes and they all have their pros and cons. This review will describe a number of assays used for evaluation of different aspects of haemostasis from a technical point of view, highlighting their methodology and what they can

\footnotetext{
* Correspondence: sofia.ramstrom@liu.se

${ }^{3}$ Department of Clinical and Experimental Medicine, Linköping University, Linköping, Sweden

Full list of author information is available at the end of the article
}

and cannot measure, with conclusions summarized in Table 1.

\section{Tests of primary haemostasis Aggregometry}

In addition to the classical light transmission aggregometry that requires preparation of platelet-rich plasma, thus limiting its usefulness in the acute clinical setting, commercial tests for assessment of aggregation in whole blood have been launched. In general, the tests have been designed to monitor treatment response to the common classes of anti-platelet drugs, aspirin, $\mathrm{P}_{2} \mathrm{Y}_{12}$ (ADP- receptor) - antagonists and GPIIb/IIIa antagonists by adding arachidonic acid, ADP or a strong platelet agonist such as the thrombin PAR1 receptor-activating peptide (TRAP, amino acid sequence SFLLRN) or collagen, respectively.

In the Multiplate (Roche, Switzerland) [3] the blood sample (anticoagulated with citrate or hirudin) is added to a disposable cuvette containing electrodes to which platelets adhere and aggregate following addition of collagen, TRAP, ADP, arachidonic acid or ristocetin. This causes a change in impedance which is registered. Multiplate is designed to measure aggregation in whole blood but can be used on platelet suspensions [4]. 
Table 1 Aspects of global haemostasis assays

\begin{tabular}{|c|c|c|c|c|c|c|c|c|c|c|c|c|}
\hline \multirow[t]{2}{*}{ Assay } & \multicolumn{3}{|c|}{ Sample type } & \multirow[t]{2}{*}{ Adhesion } & \multirow[t]{2}{*}{ Aggregation } & \multicolumn{4}{|c|}{ Coagulation } & \multirow[t]{2}{*}{ Endothelium } & \multirow[t]{2}{*}{ Shear } & \multirow[t]{2}{*}{ No. of citations } \\
\hline & Plasma & PRP & WB & & & Init. & Prop. & Elast. & Lysis & & & \\
\hline Multiplate & - & + & + & - & + & - & - & - & - & - & - & 250 \\
\hline VerifyNow & - & - & + & - & + & - & - & - & - & - & - & 476 \\
\hline Plateletworks & - & - & + & - & + & - & - & - & - & - & - & 26 \\
\hline Impact-R & - & - & + & + & + & - & - & - & - & - & + & 121 \\
\hline PFA-100 & - & - & + & + & + & - & - & - & - & - & + & 745 \\
\hline Perfusion chambers & - & - & + & + & + & $(+)$ & $(+)$ & - & - & $(+)$ & + & 630 \\
\hline TEG & $(+)$ & + & + & - & - & - & + & + & + & - & - & 4016 \\
\hline ROTEM & $(+)$ & + & + & - & - & - & + & + & + & - & - & 3932 \\
\hline ReoRox & $(+)$ & + & + & - & - & + & + & + & + & - & - & 28 \\
\hline Sonoclot & $(+)$ & + & + & - & - & + & + & + & + & - & - & 113 \\
\hline Thrombin generation & + & + & - & - & - & + & + & - & - & - & - & 118 \\
\hline $\mathrm{OHP}$ & + & - & - & - & - & + & $(+)$ & - & + & - & - & 23 \\
\hline Thrombodynamics & + & + & + & - & - & + & + & - & - & - & - & 11 \\
\hline
\end{tabular}

The assays ability to measure adhesion, aggregation, coagulation in terms of initiation (Init.), propagation (Prop.), clot elasticity (Elast) and fibrinolysis (Lysis). The table shows the type of sample (plasma, platelet-rich-plasma (PRP) or whole blood (WB)) that can be assessed in each assay. The table also shows if the measurement can include the contribution by endothelium and shear components. Plus (+) means yes and minus (-) means no, signs within parentheses means possible in theory, but not commonly used. For the propagation component, the perfusion chambers and the Thrombodynamics detects spatial clot propagation, whereas the other techniques detects other processes occurring after the initial clotting and first fibrin fibres have formed as propagation. To reflect how common these different assays are, we present the number of citations found on PubMed on the $30^{\text {th }}$ of November 2014.

VerifyNow (Accumetrics, USA) is a fully automated cartridge-based instrument for assessment of antiplatelet medications, with three types of test cartridges, containing ADP, arachidonic acid or TRAP. Citrated whole blood is mixed with the platelet agonist and fibrinogencoated beads. Activated platelets will bind to the beads and agglutinate and the increase in light transmittance due to this will be recorded [5].

The Plateletworks ${ }^{\circ}$ (Helena Laboratories, USA) aggregation kits are based upon comparing platelet counts within a control EDTA tube and after aggregation with ADP, arachidonic acid or collagen within citrated tubes. Results are expressed as \% aggregation or \% inhibition [6].

Over the past years a number of studies have been trying to establish the optimal test and range of platelet reactivity associated with the highest protection against thrombosis and the lowest risk of bleeding. The reported correlation between on-treatment platelet reactivity and outcome also suggested the use of platelet function testing to personalize antiplatelet therapy. Several studies have also been conducted in this field, but major clinical trials have failed to demonstrate a benefit of such a strategy in improving clinical outcomes (recently reviewed by $[7,8]$ ).

\section{Adhesion assays}

The classical adhesion test is to count platelets before and after passage of heparinised blood through a column filled with glass beads. Commercially available instruments include the platelet function analyzer 100 (PFA-100, Siemens Healthcare Diagnostics Inc., USA) and the cone and plate(let) analyzer (CPA) called Impact- $\mathrm{R}^{\circ}$ (DiaMed, Switzerland). Both of these tests measure platelet adhesion and aggregation under conditions of high shear and require anti-coagulated whole blood $[9,10]$. The PFA-100 measures the time to occlusion (CT, closure time) of blood flow through a collagen coated membrane in the presence of epinephrine or ADP. In the CPA system the sample is added to a polystyrene well and plasma proteins adheres to the surface of the well. Shear stress is applied by rotating a conical device immersed in the sample, leading to adhesion and aggregation of platelets. The platelets are visualized and quantified by staining. The results are expressed as percentage of surface covered by aggregates (SC) and average aggregate size (AS) [11]. The PFA-100 and the CPA have been shown to detect wWF disorders [3,9,12] and GPIIb/IIIa inhibitors $[6,10]$. There are also other instruments where shear can be applied, either using the cone-and-plate technology or the coaxial cylinder coquette, where the blood is placed between two coaxial cylinders where the inner one rotates to generate the shear [13].

Platelet adhesion can also be analysed using perfusion chambers [14]. The perfusion system consists of two parallel plates. One of the plates accepts a glass coverslip that can be coated with proteins, e.g. fibrinogen, collagen, vWF, laminin, or with endothelial cells. Platelet surface coverage, aggregate size and platelet rolling velocities can 
be evaluated by video microscopy or confocal microscopy. The shear can be varied which allows the coagulation process to be studied under physiological flow conditions. Ready-made flow chambers, sometimes also offering integrated pump-, imaging- and/or analysis systems are now entering the market [15]. The use of flow-based assays for assessment of haemostasis has been recently reviewed by the ISTH SSC Biorheology Subcommittee $[13,16]$. As platelet adhesion in flow-based devices require the presence of red blood cells, platelet suspensions such as platelet concentrates for transfusion cannot be easily evaluated. Therefore, we have recently proposed a novel assay where platelet activation upon adhesion to protein-coated beads can be studied using flow cytometry [17].

\section{Tests of secondary/global haemostasis}

\section{Viscoelastic haemostatic assays (VHA)}

The viscosity of the blood increases as the fibrin network forms during blood coagulation. Viscoelastic assays enables analysis of clot formation, clot elasticity development and the fibrinolysis process in real time. The elasticity of the clot depends on several factors; the contractile force exerted by the platelets during clot retraction, platelet concentration [18-20], haematocrit [18,21], fibrinogen concentration [18-20,22], FXIII [23,24] and the thrombin generation during coagulation [25]. However, it is important to emphasize that the major signal comes from platelet contractile forces and not from the fibrin network [26,27].

Thromboelastography was first described by Hartert in 1948 [28]. There are two commercial thromboelastographs,
TEG $^{\circ}$ (Haemonetics, USA) and ROTEM ${ }^{\bullet}$ (Pentapharm, Switzerland). The measuring unit of both instruments consists of a cylindrical cup, made of disposable plastic. A pin is suspended into the cup, and the pin is connected to a detector. The cup and the pin will make a forced oscillation relative each other with an angle of $4.75^{\circ}$ (Figure 1) $[25,29]$. It is not possible to measure the blood viscosity or to detect the initiation of coagulation, as the first signals appear when the pin is connected via the first fibrin fibres spanning the whole distance to the wall of the cup. The clot elasticity is expressed in $\mathrm{mm}$ in the tracing (Figure 2). The major difference between the instruments lies in the oscillation. In the TEG instrument the cup oscillates and in the ROTEM instrument the pin oscillates. The ROTEM instrument has an electronic pipette connected to the instrument to simplify pipetting of the different reagents provided, and the software provides exact step-by-step instructions to make the instrument easy to use.

Free oscillation rheometry (FOR) (MediRox AB, Sweden) is a newer technology which makes it possible to measure changes in viscosity and elasticity in clotting whole blood and in dissolving clots and to obtain results in SI-units. In this instrument $\left(\operatorname{ReoRox}^{\circ}\right)$, oscillation is initiated by a forced turn of the sample cup every 2.5 seconds (Figure 1). After a brief hold time, the sample cup is released, allowing free rotational oscillation around the longitudinal axis. An optic angular sensor records the frequency and damping of the oscillation as a function of time. FOR analysis includes simultaneous measurement of blood viscosity and thus allows detection even of the initial phases of coagulation, before

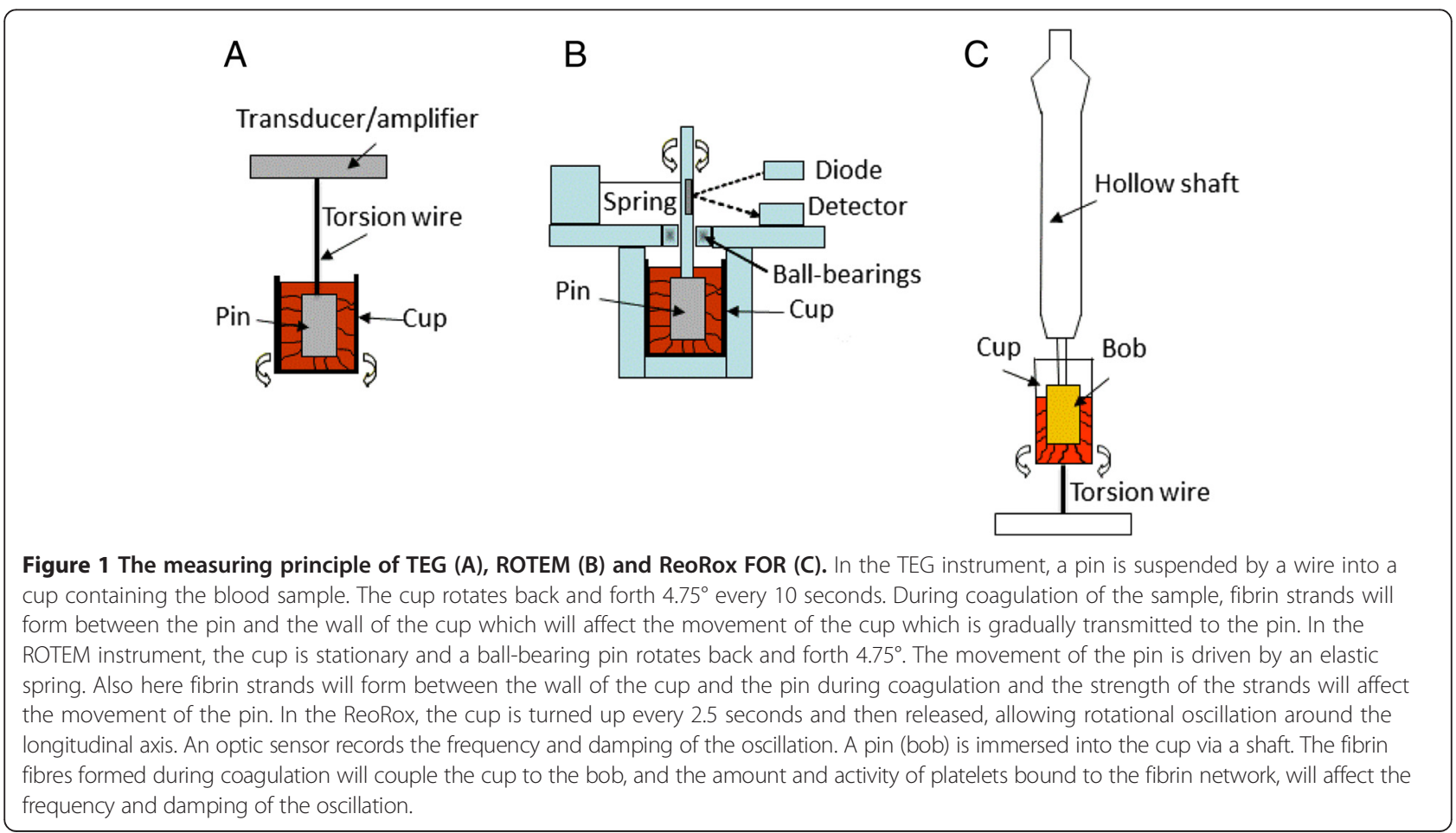




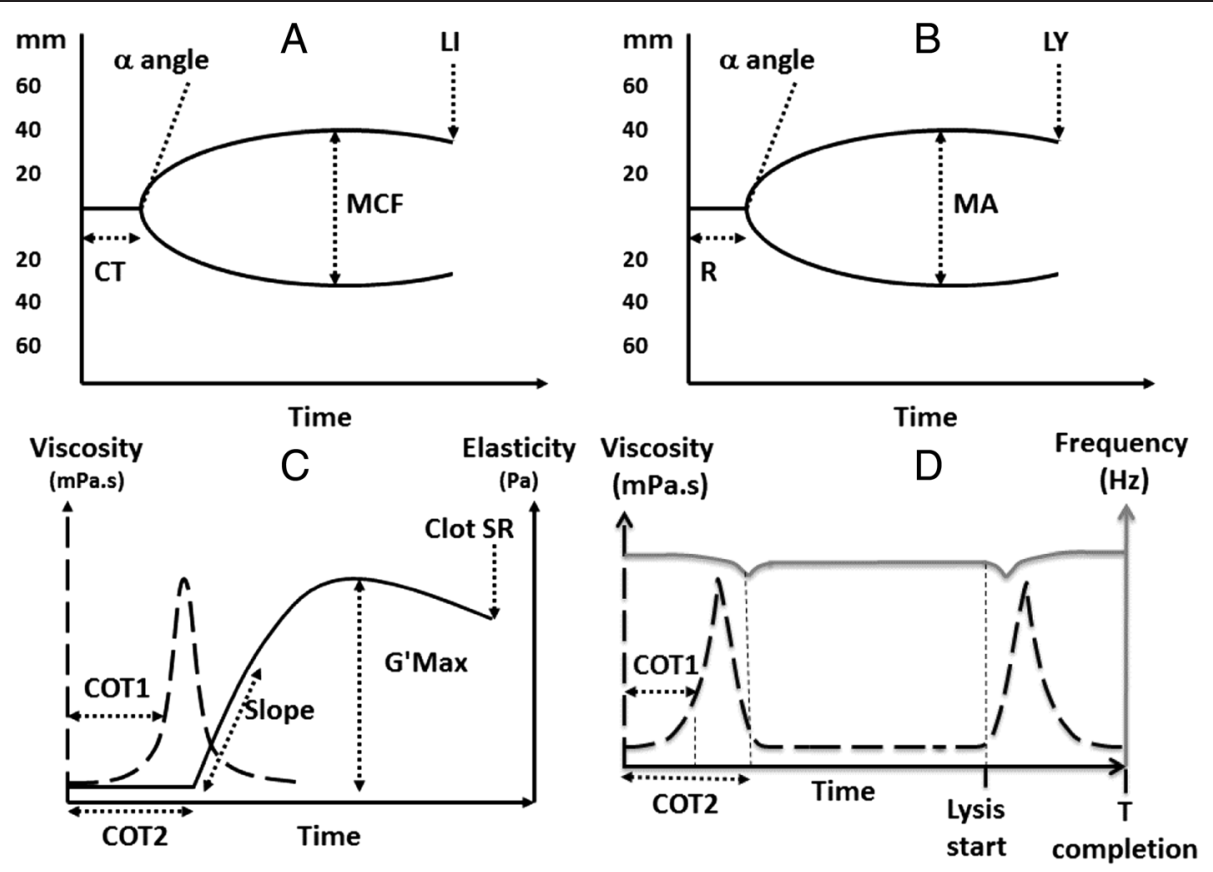

Figure 2 Tracings from TEG (A), ROTEM (B) and ReoRox (C, D) with analysis variables depicted. Clotting time as detected by TEG and ROTM (R, CT, respectively) and by ReoRox (COT1 and COT2). The elasticity propagation variable by the instruments (alfa by TEG and ROTEM and Slope by ReoRox). The maximum clot strength (MA by TEG, MCF by ROTEM and G'max by ReoRox). Fibrinolysis variables are LY30 by TEG, LI30 by ROTEM, and Clot SR and Lysis start and T completion (complete fibrinolysis) by ReoRox.

connection of the cup and bob by fibrin fibres. Goldplating of the cylindrical cup and the bob immersed in the centre is used to ensure strong, covalent binding of fibrinogen to the cup and bob. This prevents detachment when platelet contractile forces are increasing during clot retraction, which has been suggested as a potential problem in TEG and ROTEM [30]. Potential detachment, as well as differences in oscillation and detection strategies may be partial explanations to why the difference between platelet-free plasma and whole blood is smaller in ROTEM than in FOR (see Figure 3).

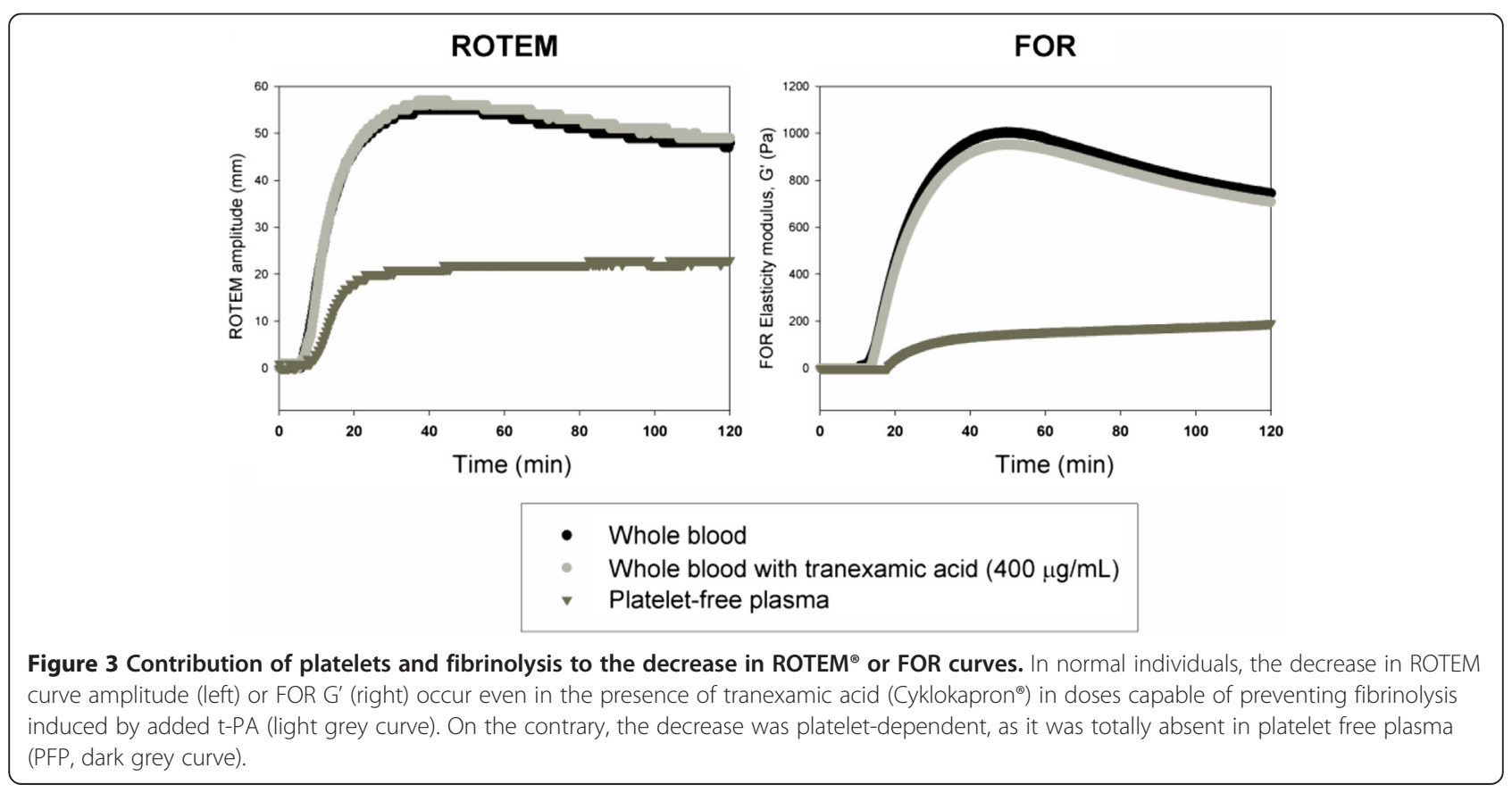


All VHA systems have a panel of different tests focusing on different aspects of the coagulation process (Table 2). The tests commercially available for TEG use kaolin or a combination of kaolin and tissue factor (TF) to activate intrinsic or extrinsic pathway of coagulation, respectively [31]. ROTEM also has reagents that can activate the intrinsic or extrinsic pathway. Both systems have tests to monitor treatment with heparin and protamine [32] as well as for evaluation of the contribution of fibrin to the clot strength $[31,33]$. None of the above tests can be used to monitor anti-platelet treatment with ADP-receptor inhibitors or aspirin. The PlateletMapping $^{\text {TM }}$ assay was introduced to monitor anti-platelet therapy by TEG. A native blood sample activated by kaolin is compared with heparinised samples where the fibrin network is formed by adding reptilase and FXIIIa and the platelets are activated by ADP or arachidonic acid [34]. This test predicted a first ischemic event after elective stenting in patients with coronary artery disease on clopidogrel and aspirin [35]. TEG has been used to monitor blood component therapy in patients undergoing cardiac, liver, or trauma surgery [36-39]. Treatment algorithms have been developed to interpret the results and guide treatment with blood components $[31,33,40]$. Low clot strength in trauma patients is associated with increased mortality [39]. For the FOR, there is a panel of tests available including tests to monitor heparin treatment and for evaluation of the contribution of fibrin to the clot strength. The coagulation is activated via the extrinsic pathway or by addition of a specific PAR1activating peptide in the TRAP test to activate platelets via thrombin receptor PAR1.The instrument has mainly been used for studies of the platelet contribution to whole blood coagulation and quality control of platelet concentrates [18,41-44]. The clinical studies published so far have been limited in number [45-48]. FOR reports a wider measuring range for elasticity as compared to thromboelastography $[18,49]$. As an example, in pregnancy the increase in clot elasticity was significant already in the first trimester utilising FOR, with an gradual increase to $52 \%$ in the third trimester [47], while no significant changes in maximal amplitude between trimesters were detected using TEG, and the maximum increase during pregnancy was less than $8 \%$ [50].

TEG and ReoRox uses abciximab, which blocks the binding of fibrinogen to the GPIIb receptor, to evaluate the contribution of fibrin to the clot strength whereas ROTEM uses cytochalasin D which inhibits the reorganisation of the platelet cytoskeleton. However, it has been shown that these substances alone might not completely block the platelet contribution to the clot strength [26] and that a combination of cytochalasin D and abciximab or tirofiban (similar mechanism of action as abciximab) more effectively blocks platelets [51].

The VHA instruments usually operate at $37^{\circ} \mathrm{C}$ but the temperature can be adjusted. This allows coagulation to be monitored in patients with hypothermia which is important since hypothermia affects coagulation [24]. Hyperfibrinolysis during trauma or major surgery is an important therapeutic target in bleeding management. VHA can be used to detect fibrinolysis by measuring the reduction in elasticity (Figure 2). However, it is important to recognise that under normal conditions, the "lysis" parameter in these instruments does not reflect ongoing fibrinolytic activity in the sample, but instead mirrors the decrease in platelet contractile force, probably due to exhaustion, as this decrease is also seen in samples treated with the fibrinolysis inhibiting drug

Table 2 TEG, ROTEM and ReoRox assays

\begin{tabular}{|c|c|c|}
\hline TEG & ROTEM & ReoRox \\
\hline KaolinTEG & InTEM & HepScreen 1 \\
\hline Kaolin (intrinsic pathway activation) & Intrinsic pathway activation, sensitive to heparin & $\begin{array}{l}\text { TP (extrinsic pathway, sensitive to } \\
\text { heparin) }\end{array}$ \\
\hline HepTEG & HepTEM & HepScreen2 \\
\hline Heparin neutralising cup & Intrinsic pathway activation + heparin neutralisation & $\begin{array}{l}\text { TP (extrinsic pathway + heparin } \\
\text { neutralization) }\end{array}$ \\
\hline RapidTEG & ExTEM & FibScreen 1 \\
\hline Kaolin + TF activation & TF activation (extrinsic pathway) & TP (extrinsic pathway) \\
\hline Functional fibrinogen TEG (FFTEG) & FibTEM & FibScreen2 \\
\hline \multirow{3}{*}{$\begin{array}{l}\text { TF activation + platelet inhibition with } \\
\text { abciximab }\end{array}$} & TF activation + platelet inhibition with cytochalasin & \multirow{3}{*}{$\begin{array}{l}\text { TP activation + platelet inhibition with } \\
\text { abciximab) }\end{array}$} \\
\hline & FibTEM+ & \\
\hline & $\begin{array}{l}\text { TF activation + platelet inhibition with cytochalasin and tirofiban } \\
\text { (under development) }\end{array}$ & \\
\hline Platelet Mapping Kit & ApTEM & ReoTrap \\
\hline$(A D P, A A)$ & (TF activation + aprotinin, verification of fibrinolysis) & PAR-1 activation \\
\hline
\end{tabular}

TEG, ROTEM and ReoRox assays and their respective sensitivities and clot initiating substances. Tissue factor (TF), thromboplastin (TP). 
tranexamic acid (Figure 3). In addition, the test used in the VHA can influence the ability of the VHA to detect fibrinolysis [52,53]. For example, RapidTEG was shown to be less sensitive than kaolin TEG to low fibrinolytic activity [52]. It has been pointed out that currently available assays to TEG and ROTEM are insufficient to detect low increase in fibrinolytic activity [54]. FOR can also detect increasing fibrinolytic activity by measuring changes in viscosity when the blood reverts back into liquid form (Figure 2) [53]. VHAs have been used to assess the effects of haemodilution with Ringer's actetate, hydroxylethyl starch (HES) and albumin on coagulation and treatment with fibrinogen and FXIII concentrates in vitro $[23,24,27,55,56]$.

The Sonoclot ${ }^{\circ}$ analyser (Sienco, Inc., USA) has a tubular probe that oscillates up and down in the whole blood sample. The resistance to movement is measured and recorded during the coagulation process [57]. Since the introduction in the 70's [58], the use of Sonoclot ${ }^{\circ}$ has been relatively limited as compared to TEG and ROTEM.

\section{Other whole blood tests}

A number of other approaches to evaluate "global haemostasis" have been described and commercialised, but not gained widespread interest. However, as it may be interesting to discuss their methodology, we will describe them briefly in this section.

The Clot Signature Analyzer ${ }^{\mathrm{rm}}\left(\mathrm{CSA}^{\mathrm{m}}\right.$; Xylum Corporation, USA) is a global haemostasis screening instrument intended for use with native whole blood [59]. The blood is passed through a thin plastic tube under pressure. Two holes are then punched in the tube, causing a fall in pressure. The platelet and fibrin clot will plug the holes and this time is recorded as the "platelet hemostasis time" (PHT). The CSA also records the clot time $(\mathrm{CT})$ as the coagulation spreads though the lumen of the tube. A subsample of the blood is also passed through a second tube with collagen fibrils and the time to reach a $50 \%$ pressure reduction in this tube is called collagen-induced thrombus formation time (CITF). Despite a relatively good sensitivity in picking out patients with known bleeding disorders in a multi-centre trial [60], the test could not help in distinguishing between platelet and coagulation factor defects.

The Gorog Thrombosis Test (GTT) [61] or thrombotic status analyser (TSA) [62] (Montrose Diagnostics, UK) adds native blood to a vertical conical tube with a hole in the bottom. The tube also contains two steel balls. Platelets are activated by shear stress (175 dyne/ $\mathrm{cm}^{2}$ ) when they pass the first large ball, and will then aggregate and initiate coagulation in the area between the balls. A light sensor records the time between blood droplets leaving the end of the tube to determine the time for occlusion, and the time for thrombolysis when blood flow starts again.

The Hemostasis Analysis System (HAS; Hemodyne, Inc., USA) is measuring the force developed by platelets as they undergo cellular contraction ("platelet contractile force", $\mathrm{PCF}^{\mathrm{Im}}$ ), and speed of clot formation in whole blood between a cup and parallel upper plate at $37^{\circ} \mathrm{C}$ [63]. The time between assay start and PCF onset is termed the thrombin generation time $\left(\mathrm{TGT}^{\mathrm{Tm}}\right)$ and is used as a surrogate marker for thrombin generation [64].

The HemoSTATUS ${ }^{\mathrm{Tw}}$ test or "platelet-activated clotting time" (Medtronic Blood Management, USA) measures acceleration of kaolin-activated clotting time (ACT) by different concentrations of platelet activating factor (PAF). The test has mainly been used for the evaluation of patients during cardiac surgery $[65,66]$, even though its usefulness for predicting blood loss has been questioned $[67,68]$.

\section{Tests performed in plasma or platelet-rich plasma Thrombin generation (CAT assay)}

The Thrombinoscope (Thrombinoscope BC, Netherlands) can be used to measure thrombin generation (TG) variables in the presence or absence of platelets. TG is carried out in a 96-well plate fluorometer. The fluorescence of the sample is compared to a calibrator. TG variables include lag-time, maximum thrombin concentration (Cmax), time required to reach $C \max (\mathrm{Tmax})$ and endogenous thrombin potential (ETP). TG is affected by deficiencies in coagulation factors II, V, VIII, IX and X but to a lesser degree by fibrinogen, FXIII and FVII [69] and the assay is not affected by haemodilution [55].

\section{Overall Hemostasis Potential (OHP)}

The overall hemostasis potential (OHP) is a plasmabased assay based on repeated spectrophotometric registration of the fibrin-aggregation curve in platelet-poor plasma containing small amounts of exogenous thrombin, tissue-type plasminogen activator, and calcium. The overall coagulation potential and overall fibrinolytic potential are supplementary parameters of OHP, with studies reported in a number of hyper- and hypocoagulable states and during anticoagulant treatment (recently reviewed in [70]).

\section{Propagation of coagulation}

A commercial instrument for detection of propagation of coagulation in plasma from a TF-coated surface has been recently introduced and described in several articles [71-73] (Thrombodynamics Analyzer ${ }^{\mathrm{Tm}}$, HemaCore, Russia). Coagulation is detected in a cuvette by timelapse image capture of light scattering from the fibrin network. By image processing and analysis, both the 
initiation (lag time in minutes) and propagation phase (initial rate of clot growth; $\mu \mathrm{m} / \mathrm{min}$ ) of the coagulation process can be measured in the same experiment. An updated version will also measure thrombin generation in the growing clot utilizing a chromogenic substrate.

\section{Discussion}

Several of the assays described are affected by platelet concentration (e.g. the PFA-100, CPA, VHA's, and VerifyNow) $[5,9,10,18-20]$. Multiplate was also shown to be affected by platelet concentration [74] but another study reported only a weak correlation within the normal range [3]. Also haematocrit affect the result of several methods including VHA's $[18,21]$. However, the aggregation assays have shown to vary in their sensitivity to haematocrit. The VerifyNow was shown to be affected by haematocrit $[75,76]$ whereas the effect on the Multiplate assay was less pronounced and depended on the agonist used in the assay [21,77] and the Plateletworks was not affected at all [6]. The perfusion chambers and CPA devices require the presence of red blood cells, which complicates the analysis of platelet suspensions or samples with a low haematocrit $[11,78,79]$. Also the PFA-100 require a haematocrit of $>10 \%$ [80].

Another difference between the methods is the use and choice of anti-coagulant which can affect the results. Several methods including the PFA-100, CPA and VerifyNow use citrated anti-coagulated blood and thus coagulation is inhibited by chelation of calcium ions $[5,75,81]$. Several anti-coagulants can be used in the perfusion chambers and might result in different results depending on the choice of anti-coagulant [14]. The VHA's have the advantage that both non-anti-coagulated whole blood and citrated blood can be used in the assay and coagulation is allowed in the citrated samples by addition of calcium. However, if reagents giving longer clotting times are used, it is important to consider and avoid unintentional contact activation in the blood collection tubes, as this might otherwise affect the test results [82]. The PFA-100 is also affected by the blood group further complicating data interpretations [3]. The recommended maximum time from blood sampling to analysis varies between the methods and may also influence the results and each manufacturer has established recommendations regarding sample stability.

The VHA's (TEG, ROTEM and ReoRox) have the advantage that they can measure coagulation, platelet function, clot retraction and fibrinolysis simultaneously. However, in contrast to the aggregation assays, VHA are in general insensitive to anti-platelet treatment with aspirin and ADP-receptor inhibitors with the exception of the Platelet Mapping assay [34]. PFA-100 has also shown variable sensitivity to aspirin and variable sensitive to clopidogrel with the ADP cartridge [80] but a newer cartridge called INNOVANCE PFA P2Y has shown promise in detecting clopidogrel resistance [83]. However, all aggregation assays, VHA's, the CPA and PFA100 are sensitive to GPIIb/IIIa inhibitors. Despite being sensitive to anti-platelet treatment the aggregometry assays selectively measures platelet function and not clot formation or fibrinolysis and Multiplate has been shown to be insensitive to factor deficiencies [84]. Both Multiplate and Plateletworks have been shown to be insensitive to fibrinogen [6,74]. The CPA in contrast is affected by fibrinogen concentration [12]. TG can be used to detect deficiencies in several coagulation factors but is less sensitive to deficiencies in fibrinogen and FXIII [69]. VHA's are affected by fibrinogen concentration [18-20,22] as well as FXIII $[23,24]$ which allows monitoring of treatment with fibrinogen and FXIII concentrates [23,24,55,56], although other methods are still the standard choice in the clinical setting. Haemodilution-associated coagulopathy can be detected by VHA's $[23,24,27,55,56]$ and aggregometry [85] but has not been detectable with TG assay [55].

A main issue to consider is the lack of flow in many of the assays (e.g. aggregometry and VHA's) [15]. Also the ones that operate with flow vary in their shear rates such as the CPA and PFA-100 $[11,12,80]$. The shear can be varied in the flow chambers and can thus mimic in vivo conditions [14]. However, the perfusion chambers and CPA have low throughput, are time consuming, complicated to use and evaluate results, and require large sample volumes, although a number of new commercial flow chambers and systems are now emerging, overcoming some of these problems [15].

Many of the methods including the aggregation assays and the PFA-100 have the disadvantage that they are not suitable for samples with low platelet concentration such as patients with hematologic malignant disease and thus are not possible to use to guide prophylactic transfusions of platelets and to assess the efficacy of a transfusion in these patients. VHA's, CPA and flow chambers have been tested in this context but further studies are warranted [47,78,86-88].

Few of the methods are recommended in guidelines, the exception is VHA's in the European guidelines by "The multidisciplinary Task Force for Advanced Bleeding Care in Trauma" for management of bleeding and coagulopathy following major trauma where viscoelastic methods are recommended (Grade 1C) to be performed to assist in characterizing the coagulopathy and in guiding haemostatic therapy [89].

In the future, new interesting options for haemostasis testing will become available. A novel cassette-based TEG instrument is in the pipeline, as well as a better test for fibrinogen in the ROTEM (FibTEM+). Another trend is the commercialisation of flow chamber devices, either as ready-made flow cells or integrated systems with 
chambers, specialised pumps and software, such as the T-TAS, VenaFlux, BioFlux and Ibidi systems. The next step may be even more miniaturised, multi-channel flow cell devices, as well as devices with patterned surfaces for platelet adhesion testing. Over the past years, these devices have evolved from being able to observe shearstress induced activation at different shear rates [90] or changing geometries [91] to devices with patterned surface coatings [92-97] and recently the combination of the two [98]. One example even includes a simple optical system for detection the onset of coagulation employing a laser and photodiode [99]. Even though this device required complex external facilities, it demonstrates one possibility for detection of coagulation in a simple point-of-care system, and more will likely follow.

The component that is missing in all current commercial devices is the endothelium, which is an important component of haemostasis in vivo, but complicated to incorporate in analyses suitable for routine use. Time will tell if addition of some components from this axis will improve the predictive power of future "global" haemostasis assays.

\section{Conclusions}

No assay available today covers all functions of the haemostatic process. Therefore, the specific clinical question and available evidence on diagnostic performance needs to guide the choice of method. As different methods have their pros and cons, the laboratory should choose the method/s giving the most relevant information for the requesting clinician, but also one being possible to perform within the times recommended to preserve sample stability and reagent performance. Many of the assays described are still labour intensive and in their current commercial form not suitable for high-throughput sample analysis or for use and interpretation by operators with little experience. Therefore, we would only recommend them to be used in units where a sufficiently large number of samples are analysed. One interesting alternative is the possibility for some of the tests to run the samples in a central lab and display the results on a screen in the operation theatre. Another problem is to produce good control materials, as the elasticity obtained in plasma control samples are much lower than the ones that will be encountered in highly elastic samples such as blood and platelet rich plasma. Many of the tests also propose the use of single samples, something that in our opinion might be questionable considering the relatively high variability in many of the methods, a reliable use of single samples should first be verified for the actual protocol and instrument to be used. Preferably, the normal reference range to be used should also be established on site with samples collected, stored and treated in the same way as the patient samples to be analysed.

\section{Competing interests}

N Tynngård is a part-time consultant to MediRox. T Lindahl is member of board, a part-time consultant and a minor shareholder of MediRox, has received reagents for research from HemaCore and lecture fees from Roche Diagnostics.

\section{Authors' contributions}

$N T$, TL and SR all contributed to the writing of this manuscript. All authors read and approved the final manuscript.

\section{Author details}

'Department of Clinical Chemistry, and Department of Clinical and Experimental Medicine, Linköping University, Linköping, Sweden. ${ }^{2}$ Department of Clinical Immunology and Transfusion Medicine, and Department of Clinical and Experimental Medicine, Linköping University, Linköping, Sweden. ${ }^{3}$ Department of Clinical and Experimental Medicine, Linköping University, Linköping, Sweden.

Received: 31 October 2014 Accepted: 12 January 2015

Published online: 05 February 2015

\section{References}

1. Tieu BH, Holcomb JB, Schreiber MA. Coagulopathy: its pathophysiology and treatment in the injured patient. World J Surg. 2007;31:1055-64.

2. Johansson PI, Ostrowski SR, Secher NH. Management of major blood loss: an update. Acta Anaesthesiol Scand. 2010;54:1039-49.

3. Seyfert UT, Haubelt H, Vogt A, Hellstern P. Variables influencing Multiplate (TM) whole blood impedance platelet aggregometry and turbidimetric platelet aggregation in healthy individuals. Platelets. 2007;18:199-206.

4. Panzer S, Jilma P. Methods for testing platelet function for transfusion medicine. Vox Sang. 2011;101:1-9.

5. van Werkum JW, Harmsze AM, Elsenberg EH, Bouman HJ, ten Berg JM, Hackeng CM. The use of the VerifyNow system to monitor antiplatelet therapy: a review of the current evidence. Platelets. 2008;19:479-88.

6. Campbell J, Ridgway H, Carville D. Plateletworks: a novel point of care platelet function screen. Mol Diagn Ther. 2008;12:253-8.

7. Franchi F, Rollini F, Cho JR, Ferrante E, Angiolillo DJ. Platelet function testing in contemporary clinical and interventional practice. Curr Treat Options Cardiovasc Med. 2014;16:300.

8. Gorog DA, Fuster V. Platelet function tests in clinical cardiology: unfulfilled expectations. J Am Coll Cardiol. 2013;61:2115-29.

9. Harrison P. The role of PFA-100 testing in the investigation and management of haemostatic defects in children and adults. $\mathrm{Br} J$ Haematol. 2005;130:3-10.

10. Varon D, Lashevski I, Brenner B, Beyar R, Lanir N, Tamarin I, et al. Cone and plate(let) analyzer: monitoring glycoprotein $\mathrm{Ilb} / \mathrm{lll}$ a antagonists and von Willebrand disease replacement therapy by testing platelet deposition under flow conditions. Am Heart J. 1998;135:S187-93.

11. Morrison A, Hornsey VS, Prowse CV, Macgregor IR. Use of the DiaMed Impact R to test platelet function in stored platelet concentrates. Vox Sang. 2007;93:166-72.

12. Shenkman B, Savion N, Dardik R, Tamarin I, Varon D. Testing of platelet deposition on polystyrene surface under flow conditions by the cone and plate(let) analyzer: role of platelet activation, fibrinogen and von Willebrand factor. Thromb Res. 2000;99:353-61.

13. Zwaginga JJ, Sakariassen KS, Nash G, King MR, Heemskerk JW, Frojmovic M, et al. Flow-based assays for global assessment of hemostasis. Part 2: current methods and considerations for the future. J Thromb Haemost. 2006;4:2716-7. Full paper available at http://www.isth.org/members/group_content_view.asp? group $=100344 \&$ id $=159093$.

14. Van Kruchten R, Cosemans JM, Heemskerk JW. Measurement of whole blood thrombus formation using parallel-plate flow chambers - a practical guide. Platelets. 2012;23:229-42.

15. Schott U, Johansson PI. II. Bringing flow into haemostasis diagnostics. Br J Anaesth. 2013;111:864-7.

16. Zwaginga JJ, Nash G, King MR, Heemskerk JW, Frojmovic M, Hoylaerts MF, et al. Flow-based assays for global assessment of hemostasis. Part 1: Biorheologic considerations. J Thromb Haemost. 2006;4:2486-7. Full paper available at http://www.med.unc.edu/isth.

17. Tynngård N, Wallstedt M, Södergren AL, Faxälv L, Ramström S. Platelet adhesion changes during storage studied with a novel method using flow 
cytometry and protein-coated beads. Platelets. 2014; Early online; doi:10.3109/09537104.2014.891728.

18. Tynngård N, Lindahl T, Ramström S, Berlin G. Effects of different blood components on clot retraction analysed by measuring elasticity with a free oscillating rheometer. Platelets. 2006;17:545-54.

19. Moganasundram S, Hunt BJ, Sykes K, Holton F, Parmar K, Durward A, et al. The relationship among thromboelastography, hemostatic variables, and bleeding after cardiopulmonary bypass surgery in children. Anesth Analg. 2010;110:995-1002.

20. Agren A, Wikman AT, Holmstrom M, Ostlund A, Edgren G. Thromboelastography (TEG(R)) compared to conventional coagulation tests in surgical patients-a laboratory evaluation. Scand J Clin Lab Invest. 2013;73:214-20

21. Bochsen L, Johansson PI, Kristensen AT, Daugaard G, Ostrowski SR. The influence of platelets, plasma and red blood cells on functional haemostatic assays. Blood Coagul Fibrinolysis. 2011;22:167-75.

22. Lang T, Johanning K, Metzler H, Piepenbrock S, Solomon C, Rahe-Meyer N, et al. The effects of fibrinogen levels on thromboelastometric variables in the presence of thrombocytopenia. Anesth Analg. 2009;108:751-8.

23. Nielsen VG. Colloids decrease clot propagation and strength: role of factor XIII-fibrin polymer and thrombin-fibrinogen interactions. Acta Anaesthesiol Scand. 2005;49:1163-71.

24. Winstedt D, Tynngard N, Olanders K, Schott U. Free oscillation rheometry monitoring of haemodilution and hypothermia and correction with fibrinogen and factor XIII concentrates. Scand J Trauma Resusc Emerg Med. 2013;21:20.

25. Johansson PI, Stissing T, Bochsen L, Ostrowski SR. Thrombelastography and tromboelastometry in assessing coagulopathy in trauma. Scand J Trauma Resusc Emerg Med. 2009;17:45.

26. Lang T, Toller W, Gutl M, Mahla E, Metzler H, Rehak P, et al. Different effects of abciximab and cytochalasin D on clot strength in thrombelastography. J Thromb Haemost. 2004;2:147-53.

27. Tynngård N, Berlin G, Samuelsson A, Berg S. Low dose of hydroxyethyl starch impairs clot formation as assessed by viscoelastic devices. Scand Clin Lab Invest. 2014;74:344-50.

28. Hartert H. Not Available. Klin Wochenschr. 1948;26:577-83.

29. Mallett SV, Cox DJ. Thrombelastography. Br J Anaesth. 1992;69:307-13.

30. Bolliger D, Seeberger MD, Tanaka KA. Principles and practice of thromboelastography in clinical coagulation management and transfusion practice. Transfus Med Rev. 2012;26:1-13.

31. Schochl H, Voelckel W, Grassetto A, Schlimp CJ. Practical application of point-of-care coagulation testing to guide treatment decisions in trauma. J Trauma Acute Care Surg. 2013;74:1587-98.

32. Mittermayr M, Margreiter J, Velik-Salchner C, Klingler A, Streif W, Fries D, et al. Effects of protamine and heparin can be detected and easily differentiated by modified thrombelastography (Rotem): an in vitro study. Br J Anaesth. 2005;95:310-6.

33. Gorlinger K, Dirkmann D, Hanke AA. Potential value of transfusion protocols in cardiac surgery. Curr Opin Anaesthesiol. 2013;26:230-43.

34. Swallow RA, Agarwala RA, Dawkins KD, Curzen NP. Thromboelastography: potential bedside tool to assess the effects of antiplatelet therapy? Platelets. 2006;17:385-92.

35. Gurbel PA, Bliden KP, Navickas IA, Mahla E, Dichiara J, Suarez TA, et al. Adenosine diphosphate-induced platelet-fibrin clot strength: a new thrombelastographic indicator of long-term poststenting ischemic events. Am Heart J. 2010;160:346-54.

36. Kang YG, Martin DJ, Marquez J, Lewis JH, Bontempo FA, Shaw Jr BW, et al. Intraoperative changes in blood coagulation and thrombelastographic monitoring in liver transplantation. Anesth Analg. 1985;64:888-96.

37. Shore-Lesserson L, Manspeizer HE, DePerio M, Francis S, Vela-Cantos F, Ergin MA. Thromboelastography-guided transfusion algorithm reduces transfusions in complex cardiac surgery. Anesth Analg. 1999;88:312-9.

38. Roullet S, Pillot J, Freyburger G, Biais M, Quinart A, Rault A, et al. Rotation thromboelastometry detects thrombocytopenia and hypofibrinogenaemia during orthotopic liver transplantation. Br J Anaesth. 2010;104:422-8.

39. Nystrup KB, Windelov NA, Thomsen AB, Johansson PI. Reduced clot strength upon admission, evaluated by thrombelastography (TEG), in trauma patients is independently associated with increased 30-day mortality. Scand J Trauma Resusc Emerg Med. 2011;19:52.

40. Kashuk JL, Moore EE, Wohlauer M, Johnson JL, Pezold M, Lawrence J, et al. Initial experiences with point-of-care rapid thrombelastography for management of life-threatening postinjury coagulopathy. Transfusion. 2012;52:23-33.

41. Tynngard N, Trinks M, Berlin G. In vitro properties of platelets stored in a small container for pediatric transfusion. Transfusion. 2014;54:1562-8.

42. Tynngård N, Lindahl TL, Trinks M, Studer M, Berlin G. The quality of platelet concentrates produced by COBE Spectra and Trima Accel cell separators during storage for 7 days as assessed by in vitro methods. Transfusion. 2008;48:715-22.

43. Tynngård N, Trinks M, Berlin G. Platelet quality after washing: the effect of storage time before washing. Transfusion. 2010;50:2745-52.

44. Tynngård N, Trinks M, Berlin G. In vitro properties of platelets stored in three different additive solutions. Transfusion. 2012;52:1003-9.

45. Kalsch T, Elmas E, Nguyen XD, Grebert N, Wolpert C, Kluter H, et al. Enhanced coagulation activation by in vitro lipopolysaccharide challenge in patients with ventricular fibrillation complicating acute myocardial infarction. J Cardiovasc Electrophysiol. 2005;16:858-63.

46. Kalsch T, Nguyen XD, Elmas E, Grebert N, Suselbeck T, Kluter H, et al. Coagulation activation and expression of CD40 ligand on platelets upon in vitro lipopolysaccharide-challenge in patients with unstable angina. Int Cardiol. 2006;111:217-23.

47. Tynngård N, Lindahl TL, Ramstrom S, Raf T, Rugarn O, Berlin G. Free oscillation rheometry detects changes in clot properties in pregnancy and thrombocytopenia. Platelets. 2008;19:373-8.

48. Solbeck S, Windelov NA, Baek NH, Nielsen JD, Ostrowski SR, Johansson PI. In-vitro comparison of free oscillation rheometry (ReoRox) and rotational thromboelastometry (ROTEM) in trauma patients upon hospital admission. Blood Coagul Fibrinolysis. 2012;23:688-92.

49. Ramström S, Rånby M, Lindahl TL. Effects of inhibition of P2Y(1) and P2Y(12) on whole blood clotting, coagulum elasticity and fibrinolysis resistance studied with free oscillation rheometry. Thromb Res. 2003;109:315-22.

50. Karlsson O, Sporrong T, Hillarp A, Jeppsson A, Hellgren M. Prospective longitudinal study of thromboelastography and standard hemostatic laboratory tests in healthy women during normal pregnancy. Anesth Analg. 2012;115:890-8.

51. Schlimp CJ, Solomon C, Ranucci M, Hochleitner G, Redl H, Schochl H. The effectiveness of different functional fibrinogen polymerization assays in eliminating platelet contribution to clot strength in thromboelastometry. Anesth Analg. 2014;118:269-76.

52. Genet GF, Ostrowski SR, Sorensen AM, Johansson PI. Detection of tPA-induced hyperfibrinolysis in whole blood by RapidTEG, KaolinTEG, and functional fibrinogenTEG in healthy individuals. Clin Appl Thromb Hemost. 2012;18:638-44.

53. Nilsson CU, Tynngard N, Reinstrup P, Engstrom M. Monitoring fibrinolysis in whole blood by viscoelastic instruments: A comparison of ROTEM and ReoRox. Scand J Clin Lab Invest. 2013;73:457-65.

54. Larsen $\mathrm{OH}$, Fenger-Eriksen $\mathrm{C}$, Ingerslev J, Sorensen B. Improved point-of-care identification of hyperfibrinolysis is needed. Thromb Res. 2012;130:690-1.

55. Fenger-Eriksen C, Tonnesen E, Ingerslev J, Sorensen B. Mechanisms of hydroxyethyl starch-induced dilutional coagulopathy. J Thromb Haemost. 2009;7:1099-105.

56. Winstedt D, Hanna J, Schott U. Albumin-induced coagulopathy is less severe and more effectively reversed with fibrinogen concentrate than is synthetic colloid-induced coagulopathy. Scand J Clin Lab Invest. 2013;73:161-9.

57. Hett DA, Walker D, Pilkington SN, Smith DC. Sonoclot analysis. Br J Anaesth. 1995:75:771-6.

58. von Kaulla K, Ostendorf $P$, von Kaulla E. The impedance machine: a new bedside coagulation recording device. J Med. 1975:6:73-88.

59. Li CK, Hoffmann TJ, Hsieh PY, Malik S, Watson WC. The Xylum Clot Signature Analyzer: a dynamic flow system that simulates vascular injury. Thromb Res. 1998;92:S67-77.

60. Fricke $W$, Kouides $P$, Kessler $C$, Schmaier AH, Krijanovski Y, Jagadeesan K, et al. A multicenter clinical evaluation of the Clot Signature Analyzer. J Thromb Haemost. 2004;2:763-8.

61. Yamamoto J, Yamashita T, Ikarugi H, Taka T, Hashimoto M, Ishii H, et al. Gorog Thrombosis Test: a global in-vitro test of platelet function and thrombolysis. Blood Coagul Fibrinolysis. 2003;14:31-9.

62. Gorog DA, Kovacs IB. Thrombotic status analyser. Measurement of platelet-rich thrombus formation and lysis in native blood. Thromb Haemost. 1995;73:514-20.

63. Carr Jr ME, Zekert SL. Measurement of platelet-mediated force development during plasma clot formation. Am J Med Sci. 1991;302:13-8. 
64. Carr ME, Martin EJ, Kuhn JG, Spiess BD. Onset of force development as a marker of thrombin generation in whole blood: the thrombin generation time (TGT). J Thromb Haemost. 2003;1:1977-83.

65. Despotis GJ, Levine V, Filos KS, Santoro SA, Joist JH, Spitznagel E, et al. Evaluation of a new point-of-care test that measures PAF-mediated acceleration of coagulation in cardiac surgical patients. Anesthesiology. 1996:85:1311-23.

66. Despotis GJ, Levine V, Saleem R, Spitznagel E, Joist JH. Use of point-of-care test in identification of patients who can benefit from desmopressin during cardiac surgery: a randomised controlled trial. Lancet. 1999;354:106-10.

67. Forestier F, Coiffic A, Mouton C, Ekouevi D, Chene G, Janvier G. Platelet function point-of-care tests in post-bypass cardiac surgery: are they relevant? Br J Anaesth. 2002;89:715-21.

68. Isgro F, Rehn E, Kiessling AH, Kretz KU, Kilian W, Saggau W. Platelet function test HemoSTATUS 2: tool or toy for an optimized management of hemostasis? Perfusion. 2002;17:27-31.

69. Matsumoto T, Nogami K, Shima M. Simultaneous measurement of thrombin and plasmin generation to assess the interplay between coagulation and fibrinolysis. Thromb Haemost. 2013;110:761-8.

70. Antovic A. The overall hemostasis potential: a laboratory tool for the investigation of global hemostasis. Semin Thromb Hemost. 2010;36:772-9.

71. Soshitova NP, Karamzin SS, Balandina AN, Fadeeva OA, Kretchetova AV, Galstian GM, et al. Predicting prothrombotic tendencies in sepsis using spatial clot growth dynamics. Blood Coagul Fibrinolysis. 2012;23:498-507.

72. Dashkevich NM, Ovanesov MV, Balandina AN, Karamzin SS, Shestakov PI, Soshitova NP, et al. Thrombin activity propagates in space during blood coagulation as an excitation wave. Biophys J. 2012;103:2233-40.

73. Lipets E, Vlasova O, Urnova E, Margolin O, Soloveva A, Ostapushchenko O, et al. Circulating contact-pathway-activating microparticles together with factors IXa and Xla induce spontaneous clotting in plasma of hematology and cardiologic patients. PLoS One. 2014;9:e87692.

74. Shams Hakimi C, Fagerberg Blixter I, Hansson EC, Hesse C, Wallen $\mathrm{H}_{\text {t }}$ Jeppsson A. Effects of fibrinogen and platelet supplementation on clot formation and platelet aggregation in blood samples from cardiac surgery patients. Thromb Res. 2014;134:895-900.

75. Elsenberg EH, van Werkum JW, van de Wal RM, Zomer AC, Bouman HJ, Verheugt FW, et al. The influence of clinical characteristics, laboratory and inflammatory markers on 'high on-treatment platelet reactivity' as measured with different platelet function tests. Thromb Haemost. 2009;102:719-27.

76. Kakouros N, Kickler TS, Laws KM, Rade JJ. Hematocrit alters VerifyNow P2Y12 assay results independently of intrinsic platelet reactivity and clopidogrel responsiveness. J Thromb Haemost. 2013;11:1814-22.

77. Ostrowski SR, Bochsen L, Windelov NA, Salado-Jimena JA, Reynaerts I, Goodrich RP, et al. Hemostatic function of buffy coat platelets in additive solution treated with pathogen reduction technology. Transfusion. 2011;51:344-56.

78. Cauwenberghs S, Feijge MA, Theunissen E, Heemskerk JW, van Pampus EC, Curvers J. Novel methodology for assessment of prophylactic platelet transfusion therapy by measuring increased thrombus formation and thrombin generation. $\mathrm{Br} J$ Haematol. 2007;136:480-90.

79. Jilma-Stohlawetz P, Horvath M, Eichelberger B, Koren D, Jilma B, Panzer S Platelet function under high-shear conditions from platelet concentrates. Transfusion. 2008;48:129-35.

80. Hayward CP, Harrison P, Cattaneo M, Ortel TL, Rao AK, Platelet Physiology Subcommittee of the S, Standardization Committee of the International Society on T, Haemostasis. Platelet function analyzer (PFA)-100 closure time in the evaluation of platelet disorders and platelet function. J Thromb Haemost. 2006:4:312-9.

81. Varon D, Dardik R, Shenkman B, Kotev-Emeth S, Farzame N, Tamarin I, et al. A new method for quantitative analysis of whole blood platelet interaction with extracellular matrix under flow conditions. Thromb Res. 1997:85:283-94.

82. Ramström S. Clotting time analysis of citrated blood samples is strongly affected by the tube used for blood sampling. Blood Coagul Fibrinolysis. 2005; 16:447-52.

83. Tsantes A, Ikonomidis I, Papadakis I, Kottaridi C, Tsante A, Kalamara E, et al. Evaluation of the role of the new INNOVANCE PFA P2Y test cartridge in detection of clopidogrel resistance. Platelets. 2012;23:481-9.

84. Kong R, Trimmings A, Hutchinson N, Gill R, Agarwal S, Davidson S, Arcari M. Consensus recommendations for using the Multiplate for platelet function monitoring before cardiac surgery. Int J Lab Hematol. 2014 doi:10.1111/ ijlh.12279. [Epub ahead of print].
85. Hanke AA, Maschler S, Schochl H, Floricke F, Gorlinger K, Zanger K, et al. In vitro impairment of whole blood coagulation and platelet function by hypertonic saline hydroxyethyl starch. Scand J Trauma Resusc Emerg Med. 2011;19:12.

86. Apelseth TO, Bruserud O, Wentzel-Larsen T, Hervig T. Therapeutic efficacy of platelet transfusion in patients with acute leukemia: an evaluation of methods. Transfusion. 2010;50:766-75.

87. Johansson PI, Simonsen AC, Brown PN, Ostrowski SR, Deberdt L, Van Hoydonck $P$, et al. A pilot study to assess the hemostatic function of pathogen-reduced platelets in patients with thrombocytopenia. Transfusion. 2013:53:2043-52.

88. Horvath M, Eichelberger B, Koren D, Bohm A, Ay C, Jilma B, et al. Function of platelets in apheresis platelet concentrates and in patient blood after transfusion as assessed by Impact-R. Transfusion. 2010;50:1036-42.

89. Spahn DR, Bouillon B, Cerny V, Coats TJ, Duranteau J, Fernandez-Mondejar E, et al. Management of bleeding and coagulopathy following major trauma: an updated European guideline. Crit Care. 2013;17:R76.

90. Gutierrez E, Petrich BG, Shattil SJ, Ginsberg MH, Groisman A, Kasirer-Friede A. Microfluidic devices for studies of shear-dependent platelet adhesion. Lab Chip. 2008:8:1486-95.

91. Tovar-Lopez FJ, Rosengarten G, Westein E, Khoshmanesh K, Jackson SP, Mitchell A, et al. A microfluidics device to monitor platelet aggregation dynamics in response to strain rate micro-gradients in flowing blood. Lab Chip. 2010;10:291-302.

92. Basabe-Desmonts L, Ramstrom S, Meade G, O'Neill S, Riaz A, Lee LP, et al. Single-step separation of platelets from whole blood coupled with digital quantification by interfacial platelet cytometry (iPC). Langmuir. 2010;26:14700-6.

93. Hansen RR, Wufsus AR, Barton ST, Onasoga AA, Johnson-Paben RM, Neeves KB. High Content Evaluation of Shear Dependent Platelet Function in a Microfluidic Flow Assay. Ann Biomed Eng. 2013;41:250-62.

94. Nalayanda DD, Kalukanimuttam M, Schmidtke DW. Micropatterned surfaces for controlling cell adhesion and rolling under flow. Biomed Microdevices. 2007;9:207-14

95. Okorie UM, Diamond SL. Matrix protein microarrays for spatially and compositionally controlled microspot thrombosis under laminar flow. Biophys J. 2006:91:3474-81.

96. Van de Walle AB, Fontenot J, Spain TG, Brunski DB, Sanchez ES, Keay JC, et al. The role of fibrinogen spacing and patch size on platelet adhesion under flow. Acta Biomater. 2012;8:4080-91.

97. de Witt SM, Swieringa F, Cavill R, Lamers MM, van Kruchten R, Mastenbroek T, et al. Identification of platelet function defects by multi-parameter assessment of thrombus formation. Nat Commun. 2014;5:4257.

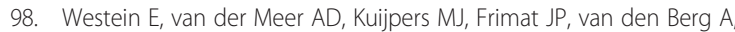
Heemskerk JW. Atherosclerotic geometries exacerbate pathological thrombus formation poststenosis in a von Willebrand factor-dependent manner. Proc Natl Acad Sci U S A. 2013;110:1357-62.

99. Li M, Ku DN, Forest CR. Microfluidic system for simultaneous optical measurement of platelet aggregation at multiple shear rates in whole blood. Lab Chip. 2012;12:1355-62.

\section{Submit your next manuscript to BioMed Central and take full advantage of:}

- Convenient online submission

- Thorough peer review

- No space constraints or color figure charges

- Immediate publication on acceptance

- Inclusion in PubMed, CAS, Scopus and Google Scholar

- Research which is freely available for redistribution 